\title{
Call for papers - 2021 special issue Tobacco and vaping prevention and control in Canada
}

Tweet this article

\section{Submission deadline extended!}

Editors: Jennifer O’Loughlin (University of Montreal), Thierry Gagné (University College London) and Robert Geneau (Editor-in-Chief, Health Promotion and Chronic Disease Prevention in Canada Journal, Public Health Agency of Canada)

It is estimated that more than 45000 Canadians die from a tobacco-related disease each year, ${ }^{1}$ making tobacco use the leading preventable cause of premature death in Canada. ${ }^{2}$ In recent years, the growing use of vaping products, especially among youth, has also raised significant public health concerns. There is emerging evidence that vaping products are not without risks for individual users, with more research needed to determine the long-term risks. The electronic cigarette market, if left to expand without an appropriate mix of regulations in place, could also threaten the "Tobacco Endgame." 3,4 Tobacco and vaping control policies are now largely intertwined.

Canada continues to implement comprehensive tobacco control policies and programs as part of its commitment to reach a national target of less than $5 \%$ tobacco use by $2035 .{ }^{5}$ Regulations on vaping products have also been introduced in recent years at the federal level and across several provinces and territories, with one of the clear aims being to curb the use of vaping products among youth.

The objective of this special issue is to disseminate current and emerging scientific evidence on tobacco and vaping-related epidemiology, prevention and control, with a focus on youth. To this effect, Health Promotion and Chronic Disease Prevention in Canada: Research, Policy and Practice seeks relevant topical research articles that present new findings or synthesize existing evidence on:

- Policies, interventions and regulations related to tobacco and/or vaping initiation, use and consumption, and cessation, including tobacco and vaping-related policy gaps and implementation challenges;

- Health inequalities in tobacco/vaping use and related harms; and

- Associations between the use of vaping products, smoking cessation and harm reduction behaviours in both smokers and non-smokers.

International submissions will be considered if they include Canadian data, results (e.g. as part of global comparisons) and/or evidencebased discussion of implications for public health in Canada.

Consult the journal's website for information on invited article types and detailed submission guidelines for authors. Kindly refer to this call for papers in your cover letter. All manuscript submissions, pre-submission inquiries and questions about suitability or scope should be directed to PHAC.HPCDP.Journal-Revue.PSPMC.ASPC@canada.ca.

Submission Deadline: April 30 2021.

\section{References}

1. Health Canada. Canada's tobacco strategy [Internet]. Ottawa (ON): Health Canada; [modified 2020 Jan 10; cited 2020 Nov 20]. Available from: https://www.canada.ca/en/health-canada/services/publications/healthy-living/canada-tobacco-strategy.html

2. Health Canada. Consultation on the future of tobacco control in Canada: what we heard. Ottawa (ON): Health Canada; 2017. Available from: https://www.canada.ca/en/health-canada/services/publications/healthy-living/consultation-future-tobacco-control -what-we-heard.html

3. McDaniel PA, Smith EA, Malone RE. The tobacco endgame: a qualitative review and synthesis. Tob Control. 2016;25:594-604. https://doi.org/10.1136/tobaccocontrol-2015-052356

4. The Tobacco Endgame Cabinet. Getting to less than 5\% by 2035: the 2019 Tobacco Endgame report. Ottawa (ON): The Canadian Lung Association; 2019. Available from: https://www.lung.ca/sites/default/files/EndGameReport-final.pdf

5. Health Canada. Overview of Canada's tobacco strategy. Ottawa (ON): Health Canada; 2018. Available from: https://www.canada .ca/en/health-canada/services/publications/healthy-living/canada-tobacco-strategy/overview-canada-tobacco-strategy.html 